\title{
CHALLENGES OF BUILDING AND MAINTAINING AN IMAGE DATABASE: A USE CASE BASED ON THE DIGITAL RESEARCH AR- CHIVE FOR BYZANTIUM (DIFAB)
}

\author{
by Nina Rannharter \& Sarah Teetor
}

\begin{abstract}
Due to the complex nature of archival images, it is an ongoing challenge to establish a metadata architecture and metadata standards that are easy to navigate and take into consideration future requirements. This contribution will present a use case in the humanities based on the Digital Research Archive for Byzantium (DiFAB) at the University of Vienna. By tracing one monument and its photographic documentation, this paper will highlight some issues concerning metadata for images of material culture, such as: various analog and digital forms of documentation; available thesauri - including problems of historical geography, multilingualism, and culturally specific terminologies -; and the importance of both precise and imprecise dating for cultural historians and their research archives.
\end{abstract}

Keywords: digital archive; metadata standards; image database; Digital Humanities; controlled vocabulary

\section{HERAUSFORDERUNGEN BEIM AUFBAU UND BEI DER PFLEGE EINER BILDDATENBANK - EIN ANWENDUNGSBEISPIEL AUS DEM DIGITALEN FORSCHUNGSARCHIV BYZANZ (DIFAB)}

Zusammenfassung: Mit Metadaten versehene, digital archivierte Bilder sind aufgrund ihrer hohen Komplexität eine ständige Herausforderung für den Aufbau von Metadatenstrukturen und für das Beibehalten von adäquaten Metadatenstandards in Bilddatenbanken. Besonders bei Bildern über eine materielle Kultur zeichnet sich diese Komplexität in den diversen Ebenen ab. Zur Verdeutlichung dieser Problematik dient ein einzelnes Monument mit seiner fotographischen Dokumentation als geisteswissenschaftliches Anwendungsbeispiel aus dem Digitalen Forschungsarchiv Byzanz (DiFAB) der Universität Wien. Unter der grundsätzlichen Berücksichtigung der künftigen Anforderungen und der einfachen Navigation von Metadaten beinhaltet dieser Beitrag u.a. die Herausforderungen mit den diversen analogen und digitalen Formen der Dokumentation, der historischen Geographie, der kulturspezifischen Terminologie sowie mit der kunsthistorischen Bedeutung einer exakten und unscharfen Datierung für Forschungsarchive.

Schlüsselwörter: digitales Archiv; Metadaten-Standards; Bilddatenbank; Digital Humanities; controlled vocabulary 


\section{Contents}

1. Introduction

2. Forms of documentation

3. Thesauri and categorization schemes

4. Dating

5. Closing remarks and future prospects

\section{Introduction}

The signs and words that constitute a language are our main form of communication regardless of historical period, the medium of their transmission, or their context. When art historians, who work primarily with physical objects and images, are charged with the task of translating their visual material, or data, into a black-on-white or a binary language, several challenges must be met. In addition to the task of registering a complex material object in few words or numbers, it can prove a challenge first to find a common language with colleagues from other disciplines, and second to convey our requirements and aspirations when it comes to generating metadata and establishing metadata standards for objects of material culture.

This paper, which was originally presented in June 2016 at the workshop of Cluster I of the e-Infrastructures Austria project, sponsored by the Austrian Federal Ministry of Science, Research and Economy (BMWFW) ${ }^{1}$, will explore some specific issues pertaining to metadata for object-centered and visual humanities based on the use case of the Digital Research Archive for Byzantium (DiFAB) ${ }^{2}$. It will focus on three main aspects of generating appropriate, high-quality, and sustainable metadata for a digital research archive rooted in material culture: the different forms of documentation; the use of thesauri and categorization schemes, specifically for historical geography, multilingualism, and culturally specific terminologies; and the importance of precise and imprecise dating.

The Digital Research Archive for Byzantium presents a particularly complicated case due to the nature of the object of investigation - the cultural sphere of the Byzantine empire, a largely Greek-speaking, Christian empire rooted in Roman state ideology that ruled much of the eastern Mediterranean area from the $4^{\text {th }}$ to $15^{\text {th }}$ centuries and whose influence persists until today in religious and artistic traditions from modern Italy to Egypt, 
and from the Middle East and the Balkans to Russia. This initiative was founded in 2005 by Lioba Theis, professor for Byzantine Art History at the Department of Art History of the University of Vienna. At first based on UNIDAM $^{3}$, the project adopted PHAIDRA ${ }^{4}$ for its long-term digital asset management and archiving in 2008, and contributed actively to early discussions of metadata requirements including the integration of internationally recognized metadata standards, such as Dublin Core. The main aims of DiFAB are:

1. to compile photographic documentation of the material culture of the Byzantine cultural sphere in digital form; and

2. to make these images available to researchers, students and interested members of the general public both now and in the future.

The principal sources of visual material constitute the historic photographs collection of the Department of Art History of the University of Vienna, which date from the late $19^{\text {th }}$ century to the 1960 s, private archives of eminent scholars in the field from the 1950s to around 2005, and born-digital photographs from field trips undertaken by project members since 2006 .

On the following pages, we will discuss the example of one monument, the Church of St. Clement in Ohrid, Former Yugoslav Republic of Macedonia (FYROM), and several digital assets that describe it in order to highlight certain necessary considerations for functional and sustainable metadata for the digital documentation of tangible cultural history.

\section{Forms of documentation}

The very complexity of creating an image database for cultural heritage is dictated by the long history of photography and developments in its use as a tool for documentation, research and teaching. In addition to the image content, to which we shall return, it is important to recognize the various types of media encountered and the different "life phases" that an originally analog image experiences (fig. 1), each with its own level of information and set of required metadata. An image, such as that in fig. 2, begins with its content, the real, three-dimensional object [1] - in this case the church building - which is then captured on a physical object, a glass-plate or film negative [2] and developed onto another physical object, a print on paper or a slide [3], before being scanned to create the digital asset [4]. Each of these stages requires core metadata pertaining to title/identifier, material, medium, dimensions, geolocation, and date, etc. 


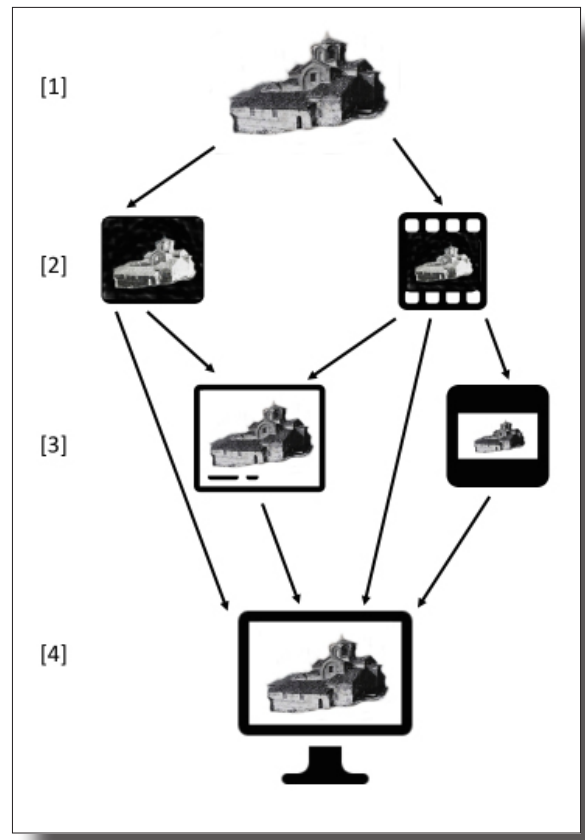

Fig. 1: Diagram of the "life phases" of an image: the real, three-dimensional object [1]; a glassplate or film negative, a physical object [2]; a print on paper or a slide, a physical object [3]; the digital asset [4]. Icons made by Dave Gandy (film), Google (slide), freepik (photographic print) and Situ Herrera (computer) from www.flaticon.com, CC 3.0 BY license; modified by authors.

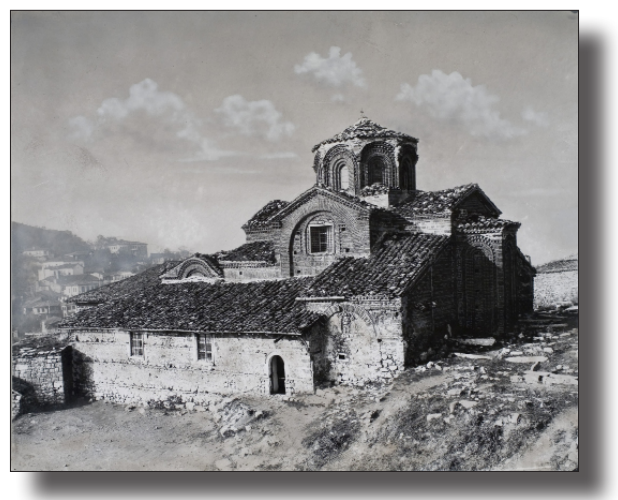

Fig. 2: Church of St. Clement, Ohrid, FYROM. View from the southeast, unknown photographer, undated (early $20^{\text {th }}$ century), collection of the Photographic Archive of the Department of Art History, University of Vienna. Digital image available at http://phaidra.univie. ac.at/o:526660 (accessed 19.5.2017), CC BY 4.0 license. 
In general, two types of digital image repositories have grown out of two different approaches: a curated, web-based archive and resource, of which Artstor ${ }^{5}$ is a popular example for art history; and digitized archives, which have been implemented by countless libraries and scientific foundations in recent years for the express purpose of making their analog collections available online. While the web-based collection that draws its metadata from multiple sources relies on a minimum of "tombstone" metadata centered on the image content - object/type, work title, artist, date, location, source and copyright - the digitized archive reflects the traditions of library and information sciences by privileging metadata related not only to title, creator, date and copyright, but also medium, reproduction number, inventory or call number, repository and provenance. As a web-based digital image archive DiFAB attempts to combine these two approaches, focusing on both the image content and the image carrier, and to enhance each digital asset through comprehensive descriptor metadata, in order to ensure retrievability and usability in future research applications.

With this combined approach, each of the up to four life stages mentioned above requires in theory its own set of standardized metadata that supply information, at the least, about the "five Ws" - what, where, who, when and why ${ }^{6}$ - of that layer. Currently, the PHAIDRA digital asset management system offers all the necessary metadata fields, many of them expandable to accommodate multiple entries. Images are uploaded and the metadata entered using the Phaidra Bagger interface, a mass upload tool; though all fields from the perspective of photograph archiving are present, their arrangement does not allow for a clear relationship of image content, image carrier(s) and digital asset with their respective metadata, ${ }^{7}$ which would be optimal from an art historical and archival standpoint. As we will see, the human user can often intuitively assign metadata regarding object/title, geography and date, etc. to the correct "life phase" though these are not currently in a clearly structured form incorporating machinereadable relationships.

\section{Thesauri and categorization schemes}

Establishing the appropriate metadata structure is the battle only half won. The next step, controlled entry, is essential to ensure regularity of metadata entries, their searchability and hopefully also their future compatibility. One tactic that DiFAB and many other online databases have adopted is the use of openly accessible thesauri and categorization schemes. At their current 
state of development, such efforts are in particular applicable to the factors "what", "where" and to some extent "who"8 - or object/title, geoinformation and person, respectively. This section will deal with DiFAB's integration of well-known thesauri and categorization tools and highlight both the advantages and drawbacks of applying research tools developed for a Western European context to a different area and period of cultural history.

\subsection{Historical geography}

Let us return to our example of the Church of St. Clement in Ohrid (FYROM). This is a structure that currently stands in the Old Town of the modern city Ohrid, an administrative seat located on a lake in the southwestern part of today's Former Yugoslav Republic of Macedonia. An inscription reveals that the church - originally dedicated to the Celebrated GodBearer (Mother of God) - was built in 1294/95 by the ethnically Albanian, Byzantine official Progon Zgur (Greek: Progonos Sgouros) and his wife Eudokia. The medieval fortress town had been erected on the site of an ancient settlement known as Lychnidos (Greek: ^úxviסos, Latin: Lychnidus). A cultural center in the Middle Ages, it was the seat of the Bulgarian Patriarchate in the late $10^{\text {th }}$ to early $11^{\text {th }} \mathrm{c}$., was contested between Byzantine, Bulgarian, Albanian, and Epirote rulers before becoming part of the Serbian empire in 1334, and eventually fell to the Ottomans in 1394, around which time the relics of St. Clement of Ohrid were transferred there and the church rededicated in his name. ${ }^{9}$ The town declined during the Ottoman period, became Bulgarian in 1878, was taken by the Kingdom of Serbia in 1912, was occupied by the Kingdom of Bulgaria during World War I, then became a southern outpost of the Kingdom of Yugoslavia in 1929 and later part of the Socialist Federal Republic of Yugoslavia until 1991 when the Republic of Macedonia declared independence.

When dealing with cultural history, the question of location or place and space in regard to their respective designations can be a tricky subject, but it is necessary to address. ${ }^{10}$ As the brief history of Ohrid and the church we are investigating demonstrates, one location can be known by many names both in the past and the present. With a view to bringing together recorded historical place names, modern place names in multiple languages and geographic coordinates that allow locations to be plotted in a GIS, DiFAB has integrated into its metadata structure the Getty Thesaurus of Geographic Names (TGN). ${ }^{11}$ In its current state the TGN offers many benefits, though its application also has some limitations especially for the historical period and areas under consideration (see table 1, below). 


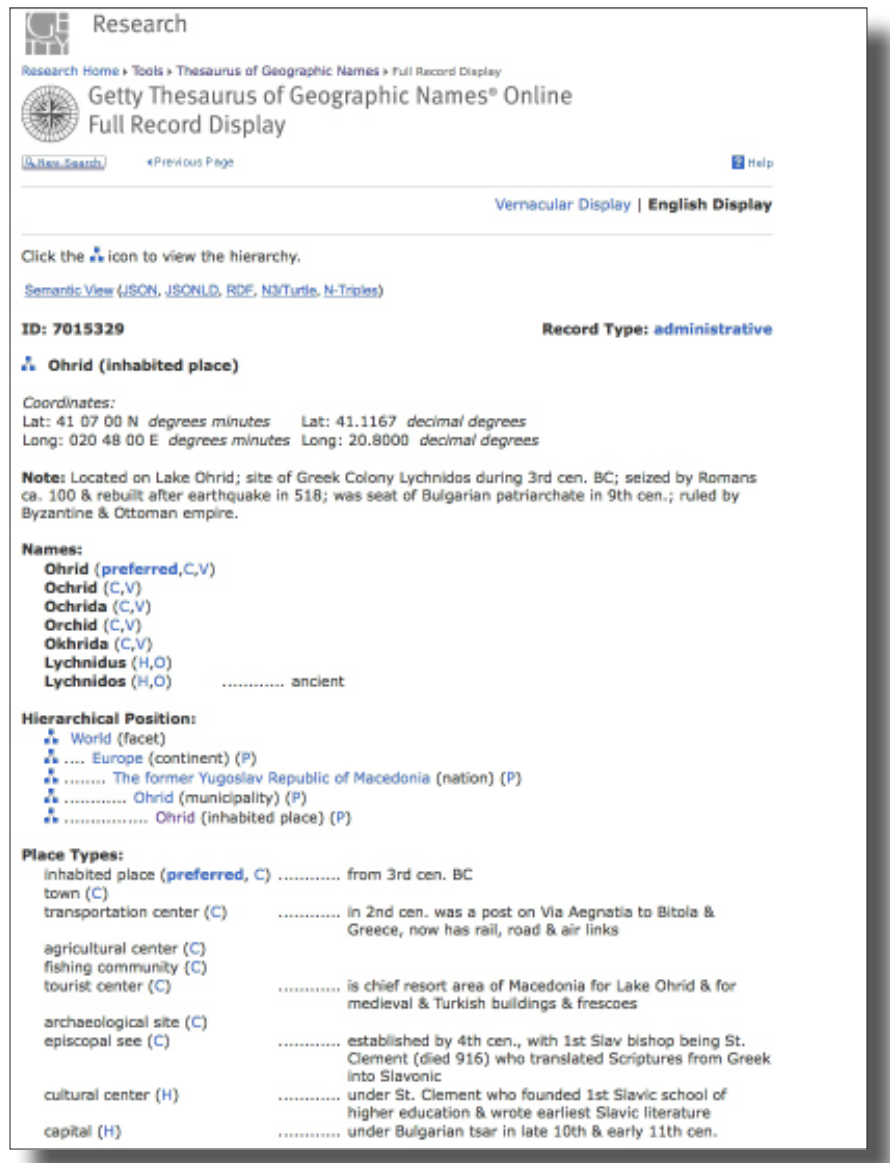

Fig. 3: Truncated screenshot of the TGN entry for "Ohrid (inhabited place)"; last accessed 2 January 2017, http://www.getty.edu/vow/TGNFullDisplay? find=\&place=\&nation=\&engl ish $=$ Y\&subjectid $=7015329$.

A search for "Ohrid" within TGN yields three results: a municipality [ID 7017378]; an inhabited place [ID 7015329]; and a lake [ID 1117570]. Each of these is categorized by its record type, defined by geographic coordinates and enhanced through the addition of variant names, a position in a geographic hierarchy, a list of place types with further historical or current details, and a list of sources and contributors (see fig. 3). One basic issue is the reliability of each entry and in particular its completeness and exactness. Another, especially for application to cultural history initiatives, is the TGN's foundation in contemporary political geography. 


\begin{tabular}{|c|c|c|}
\hline Feature & Benefits & Limitations \\
\hline ID & $\begin{array}{l}\text { + Certain identi- } \\
\text { fication } \\
\text { + Retrievable } \\
\text { + Compatibility }\end{array}$ & - Many locations missing \\
\hline Coordinates & $\begin{array}{l}\text { + Known location } \\
+ \text { Easy to map }\end{array}$ & $\begin{array}{l}\text { Accuracy and precision of } \\
\text { given coordinates: } \\
\text { - Pinpoint location, not space } \\
\text { - Only for large-scale mapping; } \\
\text { alone too imprecise for site or } \\
\text { urban mapping }\end{array}$ \\
\hline Names & $\begin{array}{l}\text { + Variant spellings } \\
\text { of transliterated } \\
\text { place name } \\
\text { + Some historical } \\
\text { place names } \\
\text { + Increased finda- } \\
\text { bility }\end{array}$ & $\begin{array}{l}\text { - "Vernacular" also translite- } \\
\text { rated (Cyrillic and Greek } \\
\text { alphabets, i.a., are supported } \\
\text { but rarely entered) } \\
\text { - Many historical place names } \\
\text { lacking (esp. medieval period) } \\
\text { - Not possible to search in } \\
\text { (non-Latin) historical or con- } \\
\text { temporary local languages }\end{array}$ \\
\hline Hierarchical position & $\begin{array}{l}\text { + Additional geo- } \\
\text { political designa- } \\
\text { tions } \\
\text { + Findable within } \\
\text { hierarchy }\end{array}$ & $\begin{array}{l}\text { - Based on modern political } \\
\text { geography }\end{array}$ \\
\hline Place types & \multicolumn{2}{|c|}{$\begin{array}{l}\text { (currently not considered by DiFAB since not } \\
\text { integrated into Phaidra) }\end{array}$} \\
\hline Sources and contributors & \multicolumn{2}{|c|}{$\begin{array}{l}\text { (currently not considered by DiFAB since not } \\
\text { integrated into Phaidra) }\end{array}$} \\
\hline
\end{tabular}

Tab. 1: Analysis of the benefits and limitations of applying TGN to the cultural sphere of the former Byzantine empire.

Other valuable resources have developed out of interest in the historical geography of the Ancient World; two prominent examples are the Digital Atlas for Roman and Medieval Civilizations (DARMC) and Pleiades. ${ }^{12}$ These have been combined in Pelagios Commons ${ }^{13}$, a community-supplied Linked Open Data initiative, with a current focus on Greek and Roman antiquity and lay- 
ered mapping approaches to this period and region. The methods of these projects are interesting for DiFAB though the content is still lacking for the Byzantine/medieval period and for some areas of eastern Europe, the Caucasus region, the Middle East and North Africa. For this reason, we are looking to contribute content based on our documentation of material sources and possibly integrate their geoinformation into our metadata in the future.

\subsection{Multilingualism}

The issue of multilingualism arises not only in regard to contemporary and historical geographic names, as we have just seen, but also when it comes to the title or designation given to a certain monument or object. The chosen example of St. Clement in Ohrid is especially complex - though not at all unique - in the fact that the structure has been known by different names throughout its long history. Dedicated originally to the Celebrated

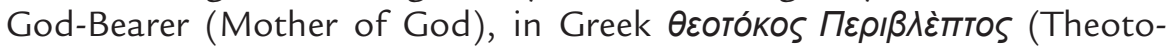
kos Peribleptos), and in Slavonic Пресвета Богородица Перивлептос (Presveta Bogorodica Perivleptos), it was rededicated to St. Clement of Ohrid at the end of the $14^{\text {th }}$ century and is also known as the Church of St.

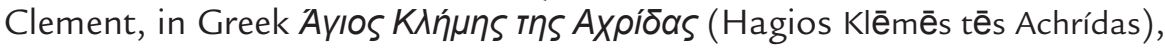
in Macedonian Свети Климент Охридски (Sveti Kliment Ohridski), and in German Klementskirche. This structure is not to be confused with two other St. Clement churches located in the same city.

To the best of our knowledge no authoritative list of names or index for Byzantine material culture exists, and the designations used in published literature depend on language, scholarly tradition and convention at the time. The task of a digital research archive, however, is to be as easily accessible as possible for all users and must therefore take into consideration different designations, multiple languages and spelling variants.

Though place names are to a certain extent covered by $\mathrm{TGN},{ }^{14}$ it is the policy of DiFAB to supply the main title in German in the format of "location, monument type and name" - for example: "Ohrid, Klementskirche (Sveti Kliment)" - and alternative titles in English, Greek, and the current local language, as well as Turkish or other languages of historical relevance. In the case of a monument with multiple historical names, these alternative titles are also supplied in at least three languages and linked to one particular digital asset. Thankfully templates can be created for metadata entry, since this effort is deemed essential - still lacking some type of index or name authority - in order to ensure better findability, ease of use for scholars, and assistance for students and those unfamiliar with these monuments. 


\subsection{Culturally specific terminologies}

For cultural history documentation and research, it helps to provide a digital asset with additional metadata, namely descriptors related to the "what" of the image content. Adding such keywords contributes to a more precise identification of the depicted object and allows for more targeted searches, thereby preparing these digital assets for potential future use in other contexts beside the digital archive itself. Again here thesauri can be helpful tools even though the terminologies they contain have their limitations, as two examples - one architectural term and one iconographic term - will show.

Architectural terminology is the common language that art historians and architects use to describe the forms and elements of a man-made structure, and in an ideal world there would be complete consensus about the terms used and their exact meaning. Unfortunately, the terms found in many thesauri, which have derived from classical archaeology and western European monuments, are not always applicable to Byzantine material culture, or can cause considerable confusion when terms carry a different meaning in a different cultural context. A case in point is the word naos (Greek: vaós). While the word in its modern Greek usage denotes the function of a building as a house of worship and can denote an ancient temple, a church, a synagogue, a mosque or a pagoda, ${ }^{15}$ for classical archaeologists the term describes a particular part of a specific type of building, namely the walledoff interior chamber of a pagan Greek temple where the statue of the deity would have stood. To a Byzantine art historian, naos describes the main central space of a Byzantine church where the congregation stands; separated from the enclosed space with the altar, it is usually domed and decorated to become "the earthly embodiment of the Christian universe."16 This distinction may not seem important until we turn to a well-known thesaurus, in this case the Getty Art and Architecture Thesaurus (AAT), which provides only the first, classical, definition. ${ }^{17}$ To include this reference in the metadata of a Byzantine monument would be akin to adding false information, since the given meaning does not fit the other cultural context.

Not only parts of buildings but also devotional and narrative images found in these buildings and elsewhere are described using shorthand terms for their content; art historians refer to conventional subjects with their characteristic imagery and symbols as iconography. Also here thesauri and categorization schemes have positive and negative aspects regarding their use. Let us take as an example a scene that was painted on the interior west wall of the Church of St. Clement in Ohrid (fig. 4). Known in the context of Byzantine art history and Greek Orthodox religion as koimēsis (Greek: 


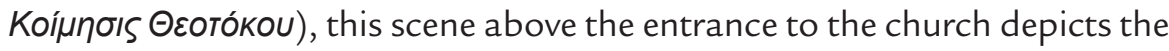
peaceful death, literally "falling asleep" or dormition, of the Mother of God who is surrounded by apostles, bishops and angels and whose soul Christ holds above her body. This painting can be located, roughly dated, and even connected to both donors and artists - a rarity in this area of study. The elements in its composition can be described and linked with thesauri such as AAT or classification systems like Iconclass, ${ }^{18}$ yet the term for the whole scene, koimēsis [theotokou], which the artist also inscribed at the top, cannot. This current lack is surprising considering that the Death of the Virgin was also a well-known theme in western medieval art. The classification "the Dormition" is contained in Iconclass [ID 73E74], and while it supplies references to the respective Biblical passages and common actors, these details and the further sub-classifications betray the different characteristics and traditions of the body of evidence upon which these classifications are based. ${ }^{19}$ As with architectural terminology, many contributions from historically less prominent areas of the field still need to be made in order to improve available thesauri and classification systems.

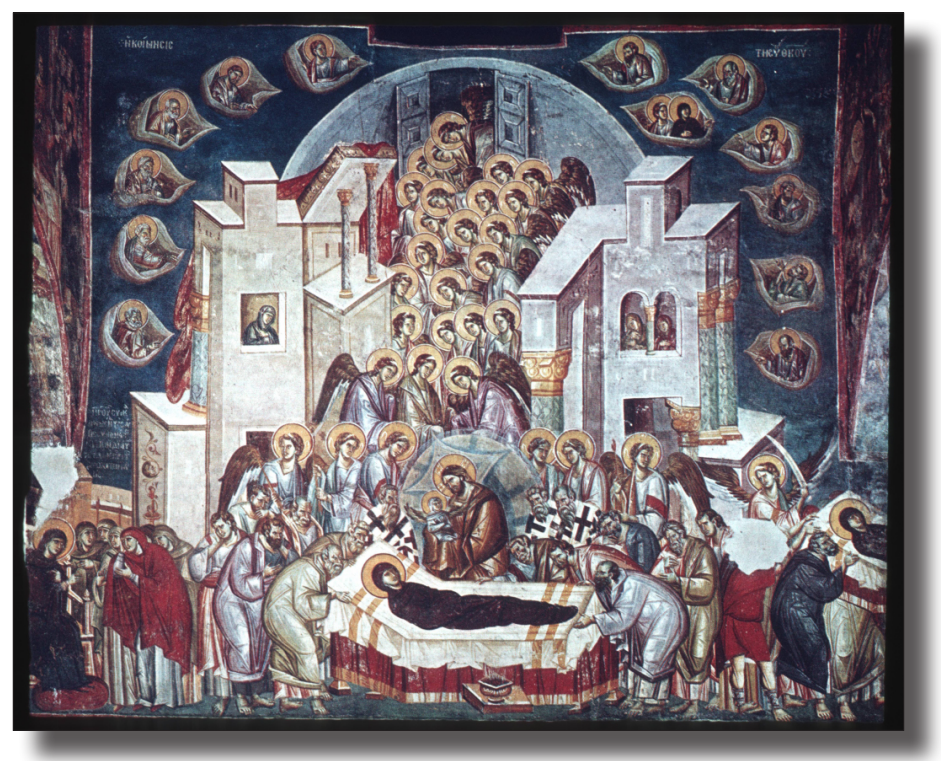

Fig. 4: Koimēsis scene on the interior west wall of the Church of St. Clement, Ohrid, painted by Michael Astrapas and Eutychios, around 1294/5 or 1305, collection of Horst Hallensleben, inv. nr. 018-099 (originally published in Djurić, Vizantijske freske u Jugoslaviji, Belgrade 1974, color plate XV). Digital image available at http://phaidra.univie.ac.at/o:526659 (accessed 19.5.2017), CC BY 4.0 license. 


\section{Dating}

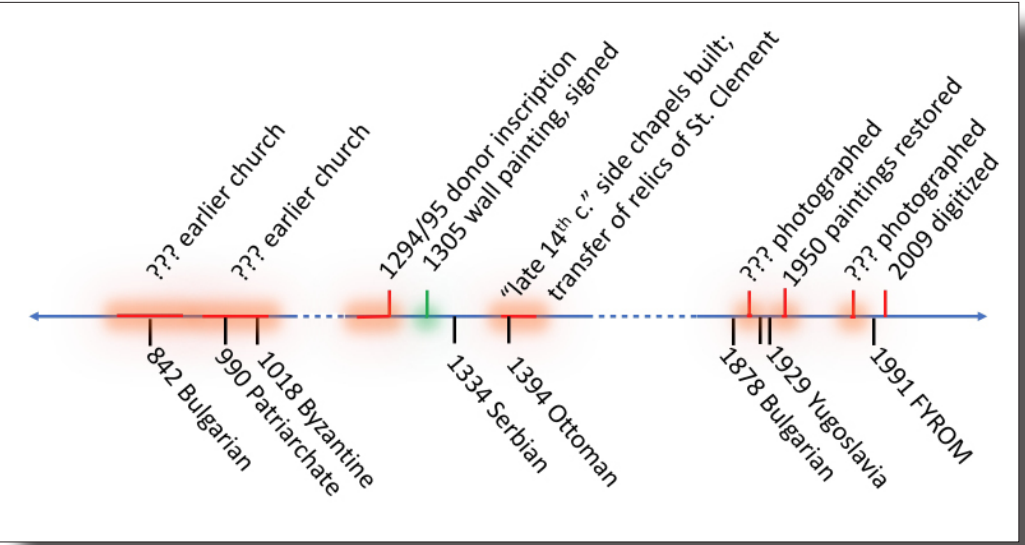

Fig. 5: Timeline for the Church of St. Clement in Ohrid: above, building history and documentation of the structure; below, political history in relation to Ohrid (not to scale). Known absolute dates and unknown precise dates are represented by a short vertical line; uncertain dates and date ranges are shown as a fuzzy horizontal line.

Returning to our "5 Ws", the question of "when" is a key aspect of metadata, and in the case of cultural history archives, dating applies to all layers of information - the original physical object, the image carrier(s) and the digital asset. The creation and manipulation of the digital asset tends to be documented and is easy to express as a specific date in the common format MYY-MM-DD. Sometimes photographic prints, slides and negatives are dated; sometimes a date range can be determined based on association with a particular individual, technical characteristics of the medium and production, or internal clues derived from the image content. When it comes to the depicted object itself, however, we must consider ourselves lucky to have an absolute or calendar date at all, or just one date at that. Antique and medieval monuments as we have inherited them seldom reflect one period of construction and are instead a composition of multiple building phases, including later additions and subtractions, redecorations and renovations.

A timeline for the Church of St. Clement in Ohrid (fig. 5) attempts to visualize the history of the structure and its documentation (above), juxtaposed with pivotal events in the political history of that location (below). Two general observations can be made. First, few precise, absolute dates directly related to the church can be identified; more often construction 
phases and events correspond to a date range that can be more-or-less precise and more-or-less conjectural. ${ }^{21}$ Second, for lack of explicit sources, archaeological and art historical research often makes use of relative chronology (establishing a sequence of events) based on the relationships between constituent parts and comparison with other monuments.

The first issue can be resolved by allowing for two metadata entries pertaining to date; the VRA Core integrates as an XML sub-element "earliestDate" and "latestDate". Where beginning and end points are approximate, however, a quantitative value is not ideal, because it gives the initial impression of certainty. ${ }^{22}$ Yet the greater challenge proves to be relative chronology, which relies on a web of contingencies and interdependencies, and the ability to capture a complex relationship not readily expressed in Dublin Core. This is an area that requires further development in order to provide comprehensive, object-related metadata that are ready and able to be used for future research applications.

\section{Closing remarks and future prospects}

It was the goal of this paper to highlight some areas of concern for cultural historians who work with material culture that have until recently received less attention in the development of metadata structures and standards. The conversion of analog documentation of monuments and artifacts poses distinctive challenges and has other requirements than born-digital assets, especially from the point of view of a research archive. Here, we chose to focus on three aspects - "life phases" and different forms of documentation, thesauri and categorization schemes, and different types of dating - to underscore the vital importance of these metadata for research endeavors in cultural and historical sciences.

Ultimately it is the aim of DiFAB, and any digital archive, to compile information related to the digital images that it curates and to prepare these digital assets - both image and metadata - in a way that focuses on accessibility and usability. As the example from the Digital Research Archive for Byzantium - the detailed investigation of the Church of St. Clement and its documentation from an object-based approach - has hopefully shown, continuing work on metadata standards and continuous contributions to Linked Open Data initiatives like the Getty Vocabularies are essential to meet these goals.

Beside compiling data to fill knowledge gaps and to expand existing structures, we are also looking toward future applications and long-life inte- 
roperability. For this reason, DiFAB is partnering with the FWF-funded "Byzantine Stone Bridges" project directed by Galina Fingarova ${ }^{23}$ to develop a pilot project based on material culture of the Byzantine cultural sphere. This collaboration will work on developing a method for the creation of a GISbased interface and research tool, and will entail a critical analysis of the metadata structure currently in place. From this collaboration we hope to gain a detailed use analysis and a proof of concept for our metadata, as well as suggestions for future best practice models in order to ensure that the efforts invested now bear fruit for upcoming research and teaching applications.

Nina Rannharter, BA Universität Wien, Institut für Kunstgeschichte E-Mail: nina.rannharter@univie.ac.at

\author{
Sarah Teetor, Bakk. BA MA \\ Universität Wien, Institut für Kunstgeschichte \\ E-Mail:sarah.teetor@univie.ac.at
}

\title{
Notes
}

1 Information on this work package of the e-Infrastructures Austria project can be found at http://e-infrastructures.at/das-projekt/work-package-cluster/cluster-i/.

2 For further information, see http://difab.univie.ac.at and for access to the database, visit https://phaidra.univie.ac.at.

3 An image database jointly initiated by the Faculty of Historical and Cultural Studies and the Faculty of Philological and Cultural Studies, both of the University of Vienna; accessible at http://unidam.univie.ac.at.

4 PHAIDRA is a digital asset management system geared toward longterm digital archiving that is based on the open source software Fedora and was developed by the IT Center of the University of Vienna in collaboration with the Vienna University Library. For further information (in German) see http://phaidraservice.univie.ac.at and for access to the database https://phaidra.univie.ac.at.

5 http://artstor.org.

6 Used here with a touch of irony, the " $5 \mathrm{Ws"} \mathrm{are} \mathrm{a} \mathrm{standard} \mathrm{series} \mathrm{of}$ questions used to gather information that is fundamentally necessary to explain an event or to solve a problem. Rooted in the rhetorical tradition of classical antiquity and its somewhat longer list of circumstances, 
these five question words plus "how" became staples of early scientific research and in the late $19^{\text {th }} \mathrm{c}$. of journalistic investigation. Although "why" seems not to fit as well as a category for metadata, it can be understood as a broader contextualization that is directly relevant to the image content and/or the image carrier, and therefore valid metadata.

7 This is a well-known caveat for working with metadata schemes based on Dublin Core. The VRA Core of the Visual Resources Association and the Network Development and MARC Standards Office of the Library of Congress makes this distinction by adding in the XML schema an upper-level wrapper denoting either a "work" (a physical object at the level of image content), "collection" (a group of "works") or "image" (a visual surrogate of a physical object, itself either a physical image carrier or a digital image file); see: http://www.loc.gov/standards/vracore/ and specifically http://www.loc.gov/standards/vracore/VRA_Core4_ Element_Description.pdf, p. 2. This places metadata in a relationship with a certain level - either depicted image content or its reproduction - though the distinction between physical image carrier and digital asset seems not to be clearly defined.

8 The issue of "who", or participating persons, as related to image content, will not be discussed here, since the main issues of coverage in thesauri and dating are mentioned elsewhere. For a comparison, see the article by Sandor Kopacsi in this issue.

9 For general information on the historical and art historical significance of the Church of St. Clement, Ohrid, see: Slobodan Ćurčić, Architecture in the Balkans: From Diocletian to Süleyman the Magnificent. New Haven, CT: Yale University Press, 2010, p. 571-577, including references in notes, p. 871-872; and "Ohrid" in: Alexander Kazhdan (ed.), Oxford Dictionary of Byzantium, Vol. 3. Oxford: Oxford University Press, 1991, p. 15141515 , especially for primary sources and older literature.

10 Here we are using the terms "location", "place" and "space" in their simplified, common meanings based on traditional geography and cartography in order to denote a fixed locality with measurable geographic coordinates (location and place) or a geographic area that can also be quantified and represented on a map (space). In this article the meaning of these words should not be confused with their use in more recent cognitive approaches in cartography or the use of the terms "place" and "space" in other areas of study such as anthropology, whereby again overly simplified - "place" designates a perceived or experienced abstract space that holds meaning, and "space" refers to an impersonal natural location. 
11 This is one of several openly accessible and Linked Open Data Getty Vocabularies developed by The Getty Research Institute; available at http://www.getty.edu/research/tools/vocabularies/tgn/.

12 DARMC, first based on the Barrington Atlas of the Greek and Roman World (2000), is available at http://darmc.harvard.edu; it has expanded into the medieval period though the data presented is richer for western and central Europe. Pleiades is a community-built, map-based index of the Ancient World based on place names found in primary and secondary sources; it also seeks to expand into other regions and periods and is available at https://pleiades.stoa.org.

13 For more information, visit http://commons. pelagios.org.

14 The two other churches are the newly erected Church of Sts. Clement and Panteleimon (Црква Св. Климент и Пантелејмон), which stands on the foundations of a $9^{\text {th }}$ century building, and the single-nave church "Small" St. Clement of Ohrid (Црква Мал Свети Климент Охридски), both also in the Old Town of Ohrid.

15 Locations that do not have an ID in TGN are added to the metadata manually - both the place name and the coordinates; a list of "missing" places and alternative names is regularly contributed to Getty Vocabularies.

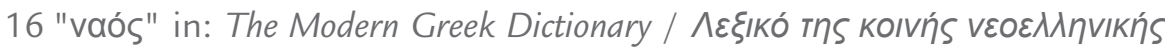
(1998), available through the website of the project "Portal for the Greek language and language education", co-financed by the European Commission: http://www.greek-language.gr/greekLang/modern_ greek/tools/lexica/triantafyllides/.

17 "Naos" in: Alexander Kazhdan (ed.), Oxford Dictionary of Byzantium, Vol. 2. Oxford: Oxford University Press, 1991, p. 1436.

18 Since the presentation of this paper in June 2016, the AAT has updated its entry for "naoi" / "naos" [ID: 300004658] to include a note on its usage in Byzantine architectural history; last accessed on 4 January 2017: http://www.getty.edu/vow/AATFullDisplay? find=naos\&logic=A ND\&note $=$ \&english $=N \&$ prev_page $=1$ \&subjectid $=300004658$.

19 Iconclass is a classification system for art and iconography that was first developed by the Dutch art historian Henri van de Waal and is currently managed by the Rijksbureau voor Kunsthistorische Documentatie / Netherlands Institute for Art History; for more information, see: http://www.iconclass.nl.

20 Byzantine iconography is almost notoriously consistent, and although some variation can be seen across time, space, and medium, the strongly symmetrical scene comprises certain core elements: the Moth- 
er of God in the foreground reclining on a bed; generally six apostles standing at the head of the bed and six at the foot; Christ in a mandorla holding up in his hands her soul, wrapped as an infant; a pair or pairs of angels at his sides; and an inscription identifying the scene. Leaving aside differences of dogma, the Catholic tradition of this scene became conflated with the Assumption and also the (heavenly) Coronation of the Virgin, which was not known in medieval Orthodox art. An example of the Dormition and Assumption in one frame can be seen on the eastern side of the tabernacle in the Gothic church of Orsanmichele in Florence, which was completed by Orcagna (Andrea di Cione) in 1359. For an image and more information, see: Nancy Rash Fabbri and Nina Rutenberg "The Tabernacle of Orsanmichele in Context," The Art Bulletin, Vol. 63, No. 3 (Sept. 1981), p. 385-405, esp. 397 (image), 399400; available at http://www.jstor.org/stable/3050142. In the western European context, the Assumption eventually gained predominance over the depiction of the death of the Virgin.

21 Overall it is quite fortuitous to find an absolute date on the monument itself, such as a painted or incised inscription, or a reference in an historical text that can be attributed to a monument with a seeming degree of certainty. Types of evidence that result in a date range are technical and stylistic analysis of the material of the monument itself and its forms - depending on the specific characteristics, this type of dating can be quite precise (within a few years) or very broad (within a couple centuries) - and secondary finds such as coins, which yield a terminus post quem or a terminus ante quem, as well as early research and historic photographic documentation which provide clues to more recent changes.

22 At the same time, qualifiers such as "about", "approximately" or "circa" - which are so prevalent in secondary literature concerned with objects of material cultural history - are also problematic due to the quantitative values that underlie them; these are less transparent and nevertheless affect search results and usability.

23 "Byzantine Stone Bridges: The material evidence and their cultural meanings" V 546 Richter Program, funded by the Austrian Science Fund (FWF) from August 2016 to July 2019; the project abstract can be found using the Project Finder feature on the website of the Austrian Science Fund: https://pf.fwf.ac.at/de/wissenschaft-konkret/projectfinder. The openly accessible web-portal for the Byzantine Stone Bridges project is currently under construction. 